\title{
Are hedgehogs like pigs, or tortoises like toads? Language-specific effects of compound structure on conceptualisation
}

\author{
Heike Wiese (heike.wiese@rz.hu-berlin.de) \\ Institut für dt. Sprache u. Linguistik, Humboldt-Universität Berlin \\ Unter den Linden 6, 10099 Berlin, Germany
}

How far can language-specific structures influence conceptualisation? After a period of time where the discussion of any 'Whorfian' effects tended to be considered of little scientific merit, the recent decade has seen a renewed interest in this question. In particular, studies have aimed to tease apart 'thinking for speaking' from general cognition (cf. Slobin 1996, Stutterheim \& Nüse 2002) and have shown that language-specific differences can often be observed in verbalisation as well as in the preverbal preparation phase of speech production, rather than in non-linguistic tasks.

However, there is also evidence for more general effects: a series of cross-cultural studies using non-linguistic tasks (Pederson et al. 1998, Levinson et al. 2002) found differences in spatial reasoning that covaried with different grammatical systems of spatial reference, suggesting that at least some aspects of grammatical organisation might have an influence on general cognition.

The present paper contributes to this discussion with evidence from a different linguistic domain, namely that of word formation: I present a study that investigated language-specific effects of compound structure on conceptualisation. Of particular interest for this topic are 'metaphorical-exocentric' compounds, that is, compounds like hedgehog that are opaque in the sense that their morphological head (hog) does not identify the conceptual category of their referent, but is only metaphorically related to it - a hedgehog is not a kind of hog, although its English name suggests this, and similarly, a tortoise is not a kind of toad, although its German name (Schildkröte, 'shield-toad') suggests this.

Do these 'misnomers' affect the conceptualisation of the respective animals, hence does the way the linguistic system represents an entity influence the way in which speakers conceptualise that entity?

Priming studies suggest that the activation of an opaque compound's head does not facilitate access to the whole compound (cf. Sandra 1990). However, there might be more subtle effects on conceptualisation. Although English speakers presumably do not believe a hedgehog to be a kind of pig, and might not pre-activate the noun when they hear 'hog' (or a semantically related word), they could conceptualise a hedgehog as more similar to a pig than speakers of a language that does not use such a compound, e.g. German and vice versa, for German speakers a tortoise might be more similar to a toad than for English speakers.

In order to investigate this, English and German speakers were tested in a non-verbal similarity task on animals. Subjects saw a series of animal pictures and had to indicate in each case which of two kinds of animals, identified in a pair of small pictures, they regarded as more similar to an animal identified in a large picture. In the experimental condition, large pictures showed animals that were named by a meta- phorical-exocentric compound in either English (hedgehogcases, e.g. a hedgehog) or German (shieldtoad-cases, e.g. a tortoise, as illustrated in Figure 1); one of the small pictures showed the animal that would be named by the compound's morphological head in that language (the related probe: the toad in Figure 1), while the other one showed an animal named by a morphologically unrelated word (the unrelated probe: the crocodile in Figure 1).

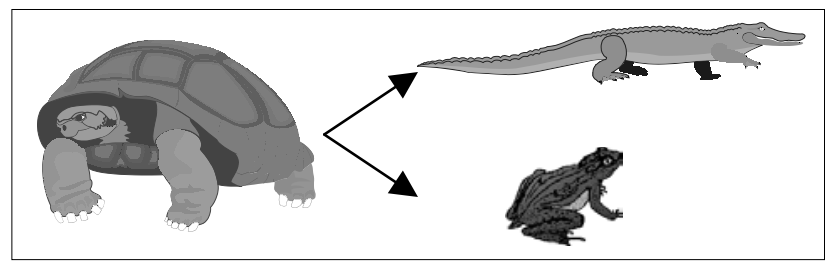

Figure 1: Are tortoises more similar to crocodiles or to toads?

English and German speakers differed significantly in their responses $(U=2254, Z=-5.04, p=0.000)$ : English speakers chose related probes more often than Germans in the 'hedgehog'-cases, and less often than Germans in the 'shieldtoad'-cases. This result suggests that compound structure had indeed an effect on the perceived similarity of referents: It suggests that morphological structure can induce subtle shifts in conceptualisation, leading to differences in the organisation of cognitive-semantic nets that reflect language-specific differences in the organisation of the lexicon.

\section{References}

Levinson, Stephen C.; Kita, Sotaro; Haun, Daniel B. M., \& Rasch, Björn H. (2002). Re-turning the tables: language affects spatial reasoning. Cognition 84(2), 155-188.

Pederson, E., Danziger, E., Wilkins, D., Levinson, S., Kita, S., \& Senft, G. (1998). Semantic typology and spatial conceptualization. Language 74, 557-589.

Sandra, Dominiek (1990). On the representation and processing of compound words: automatic access to constituent morphology does not occur. Quarterly Journal of Experimental Psychology 42A, 529-567.

Slobin, Dan I. (1996). From "thought and language" to "thinking for speaking". In J. J. Gumperz \& S. C. Levinson (Eds.), Rethinking Linguistic Relativity. Cambridge: Cambridge University Press.

Stutterheim, Christiane von, \& Nüse, Ralf (2002). Patterns of information organisation: a cross-linguistic study. In B. Behrens, C. Fabricius-Hansen \& S. Johansson (Eds.), Information Structure in a Cross-linguistic Perspective. Amsterdam: Rodopi. 